\title{
Successful use of Hemospray to control refractory duodenal diverticular bleeding
}

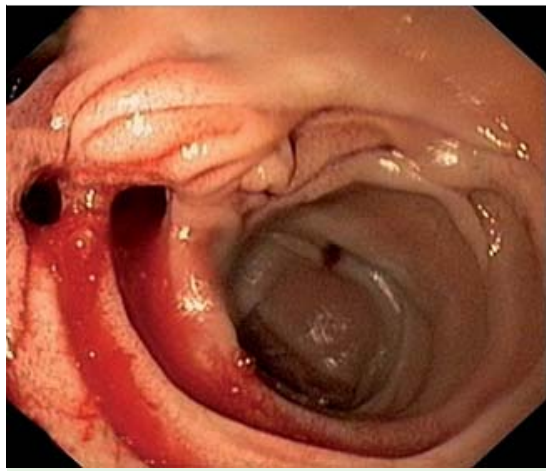

Fig. 1 Bleeding diverticulum in the descending duodenum of a 78-year-old woman on rivaroxaban medication because of atrial fibrillation.

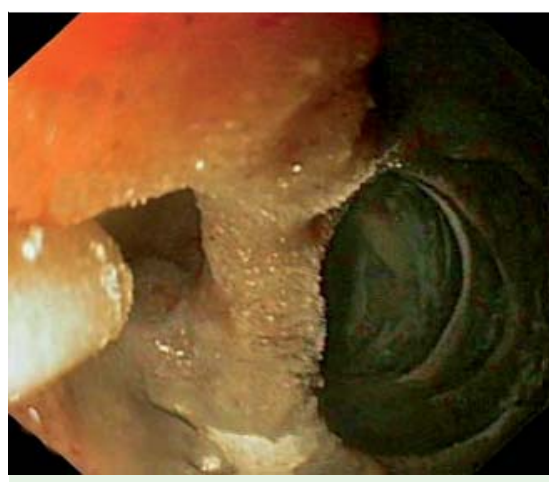

Fig. 3 Application of Hemospray with a 10-Fr catheter (left) on the third day after admission.

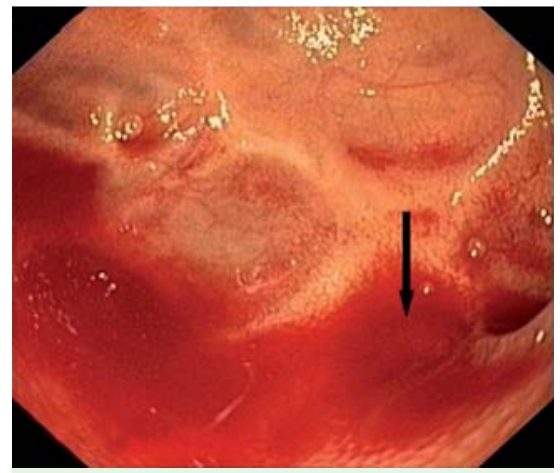

Fig. 2 Bleeding site (arrow) inside the diverticulum near the papilla.

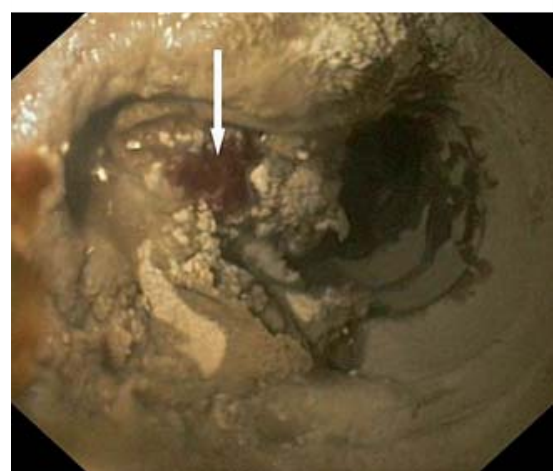

Fig. 4 Ongoing bleeding (arrow) after the first Hemospray application. Bleeding subsided after further Hemospray administration.

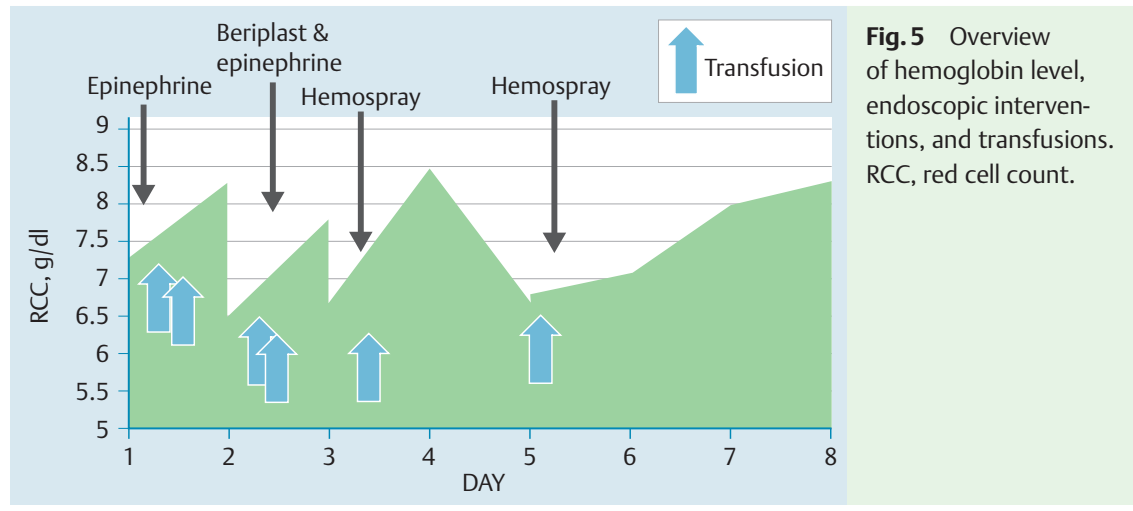

A 78-year-old woman, on rivaroxaban medication because of atrial fibrillation, was referred to our department with upper gastrointestinal bleeding. Emergency esophagogastroduodenoscopy (EGD) revealed multiple duodenal diverticula with oozing bleeding from inside a large diverticulum near the papilla ( $\bullet$ Fig. 1 and $\bullet$ Fig. 2). Because of the location, clips were not applicable, hence injection of epinephrine and later injection of fibrin glue were administered. In spite of these interventions, signs of bleeding recurred. On the third day after admission, $10 \mathrm{~g}$ of Hemospray was applied into the descending duodenum using a $10-\mathrm{Fr}$ catheter ( $\bullet$ Fig. 3 and $\bullet$ Fig. 4). After several bursts of Hemospray, bleeding stopped. During control examination 1 day later, Hemospray had disappeared from the gastrointestinal tract, but bleeding from the duodenal diverticulum had recurred. The remaining Hemospray was applied into the diverticulum and bleeding subsided. An overview of hemoglobin level, endoscopic interventions, and transfusions is shown in Fig. 5. Follow-up EGD 2 days later was unremarkable and the patient resumed an oral diet. After discharge, no further bleeding occurred during a 30-day follow-up.

Hemospray is an inorganic powder that has been shown to be effective in patients with upper and lower gastrointestinal bleeding [1-3]. It is theoretically ideal to control diverticular bleeding because complete coverage of the mucosal surface in the diverticulum can be achieved. In the literature, two cases of Hemospray as primary therapy in duodenal diverticular bleeding have been reported [2,3]. In both cases, Hemospray was unsuccessful and patients underwent rescue angiography. Effective application of Hemospray into a diverticulum can be difficult, especially if the diverticular orifice is small. In our case, full bleeding control was only achieved after the second administration. Clinical experience with repeated Hemospray applications is limited, however, in our patient this proved to be an effective treatment. Anticoagulant therapy could have contributed to delayed bleeding control although rivaroxaban had been stopped earlier.

In conclusion, Hemospray is a possible tool to achieve hemostasis in refractory diverticular bleeding and might be an option to avoid surgery or angiographic interventions.

Endoscopy_UCTN_Code_TTT_1AQ_2AZ

Competing interests: None

\section{Christian Dietrich, Rico Hochdörffer, Erik S. Fuchs, Stephan Vetter, Ralf Jakobs, Matthias Bechtler}

Medizinische Klinik C, Klinikum der Stadt Ludwigshafen, Ludwigshafen, Germany

\section{References}

1 Holster IL, Brullet E, Kuipers EJ et al. Hemospray treatment is effective for lower gastrointestinal bleeding. Endoscopy 2014; 46: $75-78$

2 Holster IL, Kuipers EJ, Tjwa ET. Hemospray in the treatment of upper gastrointestinal 
hemorrhage in patients on antithrombotic therapy. Endoscopy 2013; 45: 63 -66

3 Smith LA, Stanley AJ, Bergman JJ et al. Hemospray application in nonvariceal upper gastrointestinal bleeding: results of the survey to evaluate the application of Hemospray in the luminal tract. J Clin Gastroenterol 2013, Dec 10 [Epub ahead of print]
Bibliography

Dol http://dx.doi.org/

10.1055/s-0034-1390713

Endoscopy 2014; 46: E605-E606

(C) Georg Thieme Verlag KG

Stuttgart · New York

ISSN 0013-726X
Corresponding author

Christian Dietrich, MD

Medizinische Klinik C

Klinikum der Stadt Ludwigshafen

Bremserstr. 79

67063 Ludwigshafen

\section{Germany}

Fax: +49-621-5034114

dietricc@klilu.de 